\title{
Produção do cuidado e as relações intersubjetivas com usuários hipertensos na
} Estratégia Saúde da Família

\section{Production of care and intersubjective relationships with patients suffering of high blood pressure in the Family Health Strategy}

\section{Producción de cuidados y relaciones intersubjetivas con usuarios hipertensos en la Estrategia Salud de la Familia}

Recebido: $11 / 01 / 2020$

Aprovado: 09/06/2020

Publicado: 22/09/2020

\author{
Geanne Maria Costa Torres ${ }^{1}$ \\ Inês Dolores Teles Figueiredo \\ José Auricélio Bernardo Cândido ${ }^{3}$ \\ Antonio Germane Alves Pinto ${ }^{4}$ \\ Maria Irismar de Almeida ${ }^{5}$
}

Trata-se de um estudo descritivo, com abordagem qualitativa, realizado em um Município do interior do Estado do Ceará, Brasil, em 2016, com o objetivo de analisar a produção do cuidado e as relações intersubjetivas com usuários hipertensos na Estratégia Saúde da Família. Os dados foram coletados por um checklist para observação sistemática não participante e foram tratados pela Análise de Conteúdo Temática. Participaram 14 usuários e dois profissionais: uma enfermeira e um médico. Duas categorias emergiram: "Produção do cuidado nas relações intersubjetivas: acolhimento, diálogo, escuta, vínculo"; e, "Elementos emanados na interação interpessoal: empatia, respeito mútuo, confiança, acompanhamento nas reflexões”. Nas observações, estas práticas ainda estão centradas na doença, necessitando fortalecer o diálogo no campo das tecnologias relacionais para aprimorar a produção do cuidado sob a perspectiva da intersubjetividade na atenção. Verifica-se a necessidade de impulsionar as tecnologias leves na equipe Saúde da Família que instrumentalizam novas habilidades direcionadas à comunicação, à subjetividade e à produção do cuidado.

Descritores: Comunicação; Assistência Centrada no Paciente; Papel Profissional; Hipertensão; Estratégia Saúde da Família.

This is a descriptive study, with a qualitative approach, conducted in a city in the interior of the state of Ceará, Brazil, in 2016. It sought to analyze the production of care and the inter-subjective relationships with patients with high blood pressure in the Family Health Strategy. The data were collected through a checklist for systematic non-participant observation, treated by the Thematic Content Analysis. 14 patients and two medical professionals participated: a nurse and a doctor. Two categories emerged: "Production of care in intersubjective relationships: welcoming, dialogue, listening, bonding"; and, "Elements emanating from interpersonal interaction: empathy, mutual respect, trust, accompaniment in reflections". In the observations, these practices are still centered on the disease, with the need to strengthen the dialogue in the field of relational technologies to improve production of care from the perspective of intersubjectivity in care. There is a need to promote light technologies in the Family Health team that provide new skills for communication, subjectivity and the production of care.

Descriptors: Communication; Patient-centered Care; Professional Role; Hypertension; Family Health Strategy.

Se trata de un estudio descriptivo, con enfoque cualitativo, realizado en un municipio del interior del Estado de Ceará, Brasil, en 2016, con el objetivo de analizar la producción de cuidado y las relaciones intersubjetivas con los usuarios hipertensos en la Estrategia Salud de la Familia. Los datos se reunieron mediante un checklist para la observación sistemática no participante y fueron tratados por el Análisis de Contenido Temático. Participaron 14 usuarios y dos profesionales: una enfermera y un médico. Surgieron dos categorías: "Producción de cuidados en las relaciones intersubjetivas: acogida, diálogo, escucha, vínculo"; y, "Elementos que emanan de la interacción interpersonal: empatía, respeto mutuo, confianza, acompañamiento en las reflexiones". En las observaciones, estas prácticas siguen centradas en la enfermedad, por lo que es necesario reforzar el diálogo en el ámbito de las tecnologías relacionales para mejorar la producción de cuidados desde la perspectiva de la intersubjetividad en la atención. Se observa la necesidad de promover tecnologías ligeras en el equipo Salud de la Familia, que instrumenten nuevas habilidades dirigidas a la comunicación, la subjetividad y la producción de cuidados.

Descriptores: Comunicación; Atención Dirigida al Paciente; Rol Professional; Hipertensión; Estrategia de Salud Familiar.

1. Enfermeira. Especialista em Linhas de Cuidado em Enfermagem. Mestre em Saúde da Família. Enfermeira da Estratégia Saúde da Família de Salitre, CE, Brasil. ORCID: 0000-0003-1998-1278 E-mail: gmctorres@hotmail.com

2. Enfermeira. Especialista em Saúde Pública. Mestre em Saúde da Família. Professora do Curso de Graduação em Enfermagem da Universidade Regional do Cariri (URCA), Crato, CE, Brasil. ORCID: 0000-0002-7280-8442 E-mail: ines_dolores@hotmail.com

3. Enfermeiro. Especialista em Saúde da Família. Mestre em Saúde da Família. Enfermeiro da Estratégia Saúde da Família de Horizonte, CE, Brasil. ORCID: 0000-0003-3327-8861 E-mail: jabcauricelio60@hotmail.com

4. Enfermeiro. Especialista em Saúde da Família. Mestre em Cuidados Clínicos em Saúde. Doutor em Saúde Coletiva. Pós Doutor em Educação. Professor Adjunto do Programa de Pós Graduação Profissional em Saúde da Família da URCA, Crato, CE, Brasil. ORCID: 0000-0002-4897-1178 E-mail: germanepinto@hotmail.com

5. Enfermeira. Especialista em Psicodrama Terapêutico e Pedagógico. Mestre em Educação. Doutora em Enfermagem. Professora Adjunta da Universidade Estadual do Ceará, Fortaleza, CE, Brasil. ORCID: 0000-0001-9436-6975 E-mail: irismaruece@gmail.com 


\section{INTRODUÇÃO}

$\mathbf{N}$

o trabalho das equipes de Saúde da Família, o processo de cuidar revela um conjunto de atividades prioritárias, como atendimento individual e em equipe, educação em saúde e em serviço, coordenação da equipe e procedimentos; e rotineiras, as visitas domiciliares, reuniões em equipe e com a gestão, marcação de consultas e exames especializados, supervisão, monitoramento e avaliação das ações. Tais atividades podem impactar diretamente na oferta do cuidado aos usuários dos serviços ${ }^{1}$.

Além dos aspectos técnicos que norteiam o cotidiano das práticas de saúde, os profissionais que atuam na Estratégia Saúde da Família (ESF) devem estar atentos às subjetividades presentes nas redes relacionais para que aconteça o cuidado, pois as relações humanas $^{2}$ são consideradas como princípio primordial para a compreensão do cuidado de si, uma vez que perpassa o processo de relacionamento mútuo entre os indivíduos, valorizando desta forma, a troca interpessoal que ajuda a proteger a subjetividade e, por sua vez, a saúde.

No contexto da saúde, as cartografias do processo de trabalho buscam visibilizar, por meio das relações que se constituem nesse território, as subjetividades que se atravessam, a manifestação do diferente, a produção desejante dos fluxos de cuidado, e também de "não cuidado", o contraditório, o inesperado, desvios, estranhamentos, que traduzem o saber-fazer diante do mundo que produz o cuidado nos seus distintos cenários ${ }^{3}$.

A produção do cuidado deve permear os diferentes espaços construídos em diferentes momentos de atuação dos profissionais que trabalham na ESF, na perspectiva de valorização das subjetividades singulares e coletivas, e é substancial para potencializar as práticas de saúde por meio de relações mais acolhedoras, humanizadas e horizontalizadas.

As pessoas devem ser cuidadas como sujeitos, na singularidade de sua vida, seus devires, sua história, seus anseios, conflitos e delírios, sem tentar enquadrá-las, organizá-las em uma estrutura rígida, burocrática, centrada apenas nos sintomas ${ }^{4}$, pois o trabalho do cuidado $^{5}$ transcende ao técnico e prescrito, estando em suas ações implicado o afeto, a inteligência e a subjetividade do trabalhador.

Entendido como o alicerce de nossas relações interpessoais, o cuidado, associa-se à prática de comunicar-se. A comunicação, em suas variadas formas, tem um papel de instrumento de significância humanizadora e, para tal, a equipe precisa estar disposta e envolvida para estabelecer essa relação e entender que é primordial reconhecer o cliente como sujeito protagonista do cuidado 6 . 0 espaço intersubjetivo estabelecido nesta relação permite a comunicação e a interação interpessoal que possibilita transformar as práticas do cuidado em saúde.

A comunicação é uma ferramenta importante no processo de produção da saúde, sendo necessário que os profissionais que trabalham na ESF apropriem-se, adequadamente, do uso das tecnologias leves para que as relações intersubjetivas se estabeleçam de forma efetiva e eficaz, considerando seu caráter potencializador na oferta de uma assistência de qualidade, impactando, positivamente, no estado de saúde dos usuários/família/comunidade.

Nesse cenário, as equipes devem buscar resolver o problema de saúde do usuário, ou ajudá-lo a acessar o serviço que supostamente resolveria seu problema, portanto, elas devem ser também resolutivas e porta de entrada para outros serviços do sistema7. Estas ferramentas devem assumir o comando da produção do cuidado, servindo como dispositivo potencializador para uma lógica de trabalho que valoriza as subjetividades e as singularidades dos sujeitos envolvidos no processo de trabalho ${ }^{8}$.

Nesta perspectiva, interessa aqui a abordagem dessa temática, pela importância em revitalizar as práticas de saúde, permitindo uma abertura humana, empática e respeitosa com o usuário, sedimentada pelo acolhimento, vínculo, escuta, compromisso, respeito e ética, pois o ato do cuidar ${ }^{9}$ possui representatividade nas diferentes dimensões do ser humano, seja física, psicológica, emocional e espiritual, assim, o mesmo deve ser considerado em sua complexidade, valorizando as necessidades, singularidades e particularidades do ser humano. 
0 estabelecimento das relações, do processo comunicacional, do acolhimento e da construção do vínculo são elementos importantes que deveriam se fazer presentes nas Unidades Básicas de Saúde (UBS) ${ }^{10}$. Na magnitude que representa a produção do cuidado e as relações intersubjetivas na ESF, os profissionais de saúde devem fortalecer as tecnologias relacionais no processo de trabalho, em especial, com os hipertensos que requerem mudanças no estilo de vida e cuidados diários para o controle adequado da doença, por meio de uma ligação mais afetuosa com o outro, sob a lógica do vínculo, respeito mútuo, empatia, escuta receptiva e acompanhamento de quem está sendo cuidado.

A comunicação entre os trabalhadores e usuários é um elemento que pode garantir o sucesso das práticas de cuidado ou conduzir ao seu fracasso, a depender da lógica quem a orienta, ou seja, se está voltada para o entendimento entre os sujeitos envolvidos, o agir comunicativo, ou exclusivamente para o êxito técnico, instrumental ${ }^{11 .}$

Diante disso, questiona-se: Como acontece a produção do cuidado e as relações intersubjetivas com usuários hipertensos na ESF? Assim considerado, este estudo tem como objetivo analisar a produção do cuidado e as relações intersubjetivas com usuários hipertensos na Estratégia Saúde da Família.

\section{MÉTODO}

Este é um estudo descritivo com abordagem qualitativa, tendo como cenário uma equipe de Saúde da Família, em um Município do interior do Estado do Ceará, Brasil. Os dados foram coletados no período de abril a maio de 2016. A pesquisa descritiva ${ }^{12}$ permite observar, registrar, analisar, correlacionar fatos ou fenômenos sociais e estabelecer relações entre as variáveis sem manipulá-las. E, a abordagem qualitativa se preocupa em analisar e interpretar aspectos mais profundos, descrevendo a complexidade do comportamento humano. Fornece análise mais detalhada sobre investigações, hábitos, atitudes, tendências comportamentais.

O município apresenta sete equipes de Saúde da Família (eSF), com uma cobertura de $100 \%$ da população; quatro equipes de Saúde Bucal (eSB) e um Núcleo de Apoio à Saúde da Família (NASF), para atuar de forma integrada com as equipes. Possui uma população estimada de 16.070 habitantes, distando da Capital do Ceará, Fortaleza, $585 \mathrm{~km}$. Encontra-se inserido na Macrorregião do Cariri e na 20aㅗ Microrregião do Crato, Ceará.

Para desta investigação, participaram hipertensos e profissionais da ESF. Para os usuários, adotou-se como critérios de inclusão: estarem cadastrados na Unidade de Saúde; residirem na área de abrangência da ESF; terem acompanhamento regular por, pelo menos, seis meses consecutivos; e de exclusão: apresentarem perturbações cognitivas e serem acamados. 0 critério de inclusão para os profissionais definiu-se: atuarem na Estratégia Saúde da Família há, pelo menos, um ano; e de exclusão, estarem afastados do trabalho, por motivo de férias e/ou licença.

A coleta de dados foi realizada por meio da observação sistemática não participante, utilizando-se como instrumento um checklist contendo os grupamentos das estratégias de comunicação terapêutica: expressão, clarificação e validação ${ }^{13}$, subsidiada por um diário de campo para registro das informações referentes às observações e outras anotações percebidas nas relações intersubjetivas, como empatia, respeito mútuo, confiança, escuta receptiva e acompanhamento do paciente em suas reflexões. Cada participante foi observado, em média, por 15 minutos, totalizando 210 minutos de registro.

As técnicas de comunicação são classificadas em três grupos: o grupo expressão ${ }^{13}$ onde estão organizadas as técnicas que ajudam à descrição da experiência e a expressão de pensamentos e sentimentos sobre ela. Nesse grupo encontram-se as seguintes técnicas: usar terapeuticamente o silêncio; ouvir reflexivamente; verbalizar aceitação; verbalizar interesse; usar frases incompletas; repetir as últimas palavras ditas pelo paciente; fazer pergunta; desenvolver a pergunta feita; usar frases descritivas; manter o paciente no mesmo assunto; permitir ao paciente que escolha o assunto; colocar em foco a ideia principal; verbalizar 
dúvidas; dizer não; estimular expressão de sentimentos subjacentes; e o uso terapêutico do humor.

No grupo de clarificação ${ }^{13}$ estão às técnicas que ajudam a esclarecer o que for expresso pelo paciente, entre elas podemos citar: estimular comparações; solicitar que esclareça termos comuns; solicitar ao paciente que precise o agente de ação; e descrever os eventos em sequência lógica.

Por sua vez, no grupo de validação ${ }^{13}$, as técnicas permitem a existência de significação comum do que é expresso, e são apresentadas como: repetir a mensagem do paciente; pedir ao paciente para repetir o que foi dito; e sumarizar o conteúdo da interação.

A observação ajuda o pesquisador a identificar e obter provas a respeito de objetivos sobre os quais os indivíduos não têm consciência, mas que orientam seu comportamento ${ }^{12}$. Além disso, permite um contato mais direcionado com a realidade.

0 material empírico foi analisado e interpretado pela Análise de Conteúdo de $\operatorname{Bardin}^{14}$, a qual fornece informações complementares ao leitor crítico de uma mensagem, norteado pelas etapas: pré-análise, exploração do material, tratamento dos resultados, inferência e interpretação.

Após leituras exaustivas para maior compreensão dos dados em análise, foram identificadas as unidades de registro que significam ${ }^{14}$ unidades a se codificar, podendo ser um tema, uma palavra ou uma frase, que guia o pesquisador na busca de informações contidas no texto. A escolha dessa técnica deu-se em virtude da valorização do significado do conteúdo das mensagens de acordo com os objetivos propostos pela pesquisa.

Para tanto, considerou-se as falas e anotações do diário de campo, trazendo reflexões que emergiram para o agrupamento adequado dos dados na construção de categorias e, a caracterização dos participantes da pesquisa.

Ao preconizar a ética em pesquisa, os hipertensos foram representados por emoções e sentimentos, como alegria, leveza, simpatia, preocupação, dentre outros, conforme as condições nos quais se encontravam no momento das consultas. Os profissionais foram identificados pelo uso das siglas (E - Enfermeiro) e (M - Médico).

A pesquisa foi realizada mediante parecer favorável do Comitê de Ética em Pesquisa, da Universidade Estadual do Ceará (UECE), sob o Parecer $n^{\circ} 1.506 .165 / 2016$, respeitando-se aos preceitos éticos que norteiam pesquisas ${ }^{15}$ em seres humanos estabelecidos na Resolução no 466/2012, do Conselho Nacional de Saúde/Ministério da Saúde.

\section{RESULTADOS}

\section{Caracterização dos participantes da pesquisa}

Participaram 14 usuários e dois profissionais da equipe, o médico e a enfermeira. Nos hipertensos houve predomínio do sexo feminino (86\%), com uma média de 59,5 anos. Na situação conjugal, 57\% eram casados. Em 71,4\% dos entrevistados eram analfabetos.

Pelos dados, percebeu-se o predomínio de mulheres durante as observações, pelo fato de serem donas de casa, tendo mais tempo de ir à unidade de saúde, bem como por apresentarem maiores cuidados com a saúde.

Pelo baixo nível de escolaridade, maior a frequência dos fatores de risco para as doenças cardiovasculares, a hipertensão arterial, observou-se a necessidade de se fortalecer a produção do cuidado e as relações intersubjetivas para minimizar os riscos à saúde advindos da pressão arterial não controlada, bem como prevenir outros agravos cardiovasculares.

Os profissionais de saúde apresentavam a idade entre 20 a 30 anos, solteiros, graduados academicamente e com pós-graduação. 0 tempo de atuação na ESF variou de dois a quatro anos, representando um tempo significativo para compreensão do território, criando vínculo e reconhecendo as especificidades e necessidades da área de abrangência. 
Duas categorias emergiram a saber: "Produção do cuidado nas relações intersubjetivas: acolhimento, diálogo, escuta, vínculo" e "Elementos emanados na interação interpessoal: empatia, respeito mútuo, confiança, acompanhamento nas reflexões".

\section{Produção do cuidado nas relações intersubjetivas: acolhimento, diálogo, escuta, vínculo}

Esta categoria apresenta a prática do cuidado e sua implicação com as relações intersubjetivas, permitindo vivenciar o acolhimento, o diálogo, a escuta, o vínculo e a interação dos envolvidos no processo comunicacional. Ao longo das observações, percebeu-se expressão das emoções, dúvidas, angústias e sofrimentos estabelecidos nas relações com o outro, sendo desvelados pelos relatos:

[...] tem me dado muito trabalho [...] (Preocupação).

A senhora quer falar mais sobre isso (...) (E).

Sofro com isso [...] (Ansiedade).

O que causa tanto sofrimento no Senhor? (M).

A doutora me dá atenção [...] (Paz).

A senhora pode continuar [...] (E).

Pelas falas, evidenciou-se um espaço de produção do cuidado contemplado por uma comunicação clara e compreensível, permitindo externar emoções, sentimentos e angústias na relação profissional de saúde-hipertenso, fundamental para o desenvolvimento de um cuidado mais humano e adequado às necessidades desses usuários. Outro fato que merece destaque é a população chamar a enfermeira de doutora, tanto pela demonstração de respeito quanto pela capacidade de liderança dentro da equipe de saúde.

No entanto, na unidade estudada, no processo de cuidado, prevaleceu o uso das tecnologias leve-duras, regado pelo respeito, vínculo e confiança nas interações dos profissionais com hipertensos. Observou-se, então, a necessidade desses profissionais, no momento em que se expressa às relações intersubjetivas, fortalecer o uso das tecnologias leves para fomentar o trabalho vivo em ato na saúde. Isso aprimora a ambiência relacional e cria espaços na produção de novas possibilidades nas práticas do cuidar.

Parece uma realidade tão longe, mas que está bem perto dos profissionais de saúde, necessitando, portanto, maior empenho nas ações direcionadas a comunicação, acolhimento, responsabilização e escuta que são peculiares à dimensão humana, tendo em vista que os hipertensos são o foco da atenção e que o reconhecimento de suas expressões subjetivas é indispensável à efetivação do cuidado.

\section{Elementos emanados na interação interpessoal: empatia, respeito mútuo, confiança, acompanhamento nas reflexões}

Esta categoria privilegia os elementos emanados na interação interpessoal, por meio das relações dialógicas e dos encontros nos distintos espaços do cuidar, primando por um cuidado acolhedor e humanizado. Manifestou-se, nas observações, um cuidado permeado de elementos contributivos à qualidade da assistência prestada aos hipertensos, conforme apreendidos nos registros:

[...] estou passando por uma situação difícil [...] (Esperança).

A senhora pode me falar o que está acontecendo [...] (E).

Pode falar [...] (M).

Fica um tempo em silêncio "[...]" depois, sorri [...] (Simpatia).

Não quero mais tomar esses remédios [...] (Carisma).

A senhora pode me dizer por que não quer mais tomar esses remédios? (M).

Não me sinto bem [...] (Carisma).

A despeito do exposto, identificou-se na prática do cuidado relações harmoniosas, acolhedoras e humanizadas. Os profissionais de saúde demonstram atenção, afeto e preocupação, solidarizando-se e sendo sensível aos problemas relatados pelos hipertensos. Além disso, perceberam-se elementos que fortalecem o relacionamento terapêutico, permitindo maior interação profissional de saúde-hipertenso que favorece, positivamente, no tratamento e no cuidado desses usuários, sendo representado nas seguintes expressões: 
Olha para o hipertenso enquanto conversa (E).

Dá abertura para o hipertenso falar (M).

Escuta atentamente o hipertenso (E).

Sorri [...], oferecendo ajuda (E). Importa-se com o que o hipertenso diz (M).

Troca a medicação e orienta medidas adequadas para o controle da doença (M).

Evidenciou-se nesses discursos que as singularidades de cada hipertenso são refletidas pela relação de empatia, respeito mútuo, confiança, escuta receptiva e acompanhamento nas suas reflexões, principalmente pela profissional de Enfermagem que estabelece o estar-com, 0 olhar, o escutar, pela sua sensibilidade e humanização no cuidar.

Neste entremeio, percebeu-se uma atenção centrada na doença, fundamentada nas medidas prescritivas e nas orientações para controle adequado da hipertensão, necessitando, portanto, a superação dessas lacunas para avançar na dimensão dos cuidados em saúde. Apesar disto, situações de "ironia", "desprezo", "julgamento", "culpabilização" e "desatenção" não foram manifestadas pelos profissionais de saúde na abordagem aos hipertensos, favorecendo maior compreensão das necessidades desses usuários.

\section{DISCUSSÃO}

Esta pesquisa foi realizada no cenário da APS, apresentando como espaço de atenção a ESF, que privilegia o trabalho em equipe, buscando assumir a função precípua de acolhida, escuta e desenvolvimento de relações interpessoais construtivas, que favorece a ampliação sobre a visão do cuidar.

$\mathrm{Na}$ análise do perfil da amostra, destacou-se que a hipertensão aumenta com o avançar da idade, sendo que pessoas na faixa etária dos 50 aos 59 anos apresentam 5,35 vezes mais chances de serem hipertensas do que as da faixa etária de 20 a 29 anos $^{16}$. Adultos com menor nível de escolaridade (sem instrução e com Ensino Fundamental incompleto) apresentam maior prevalência de HA autorreferida ${ }^{17}$. Tal fato é preocupante, pois é proporcional ao nível de conhecimento sobre prevenção dos fatores de riscos para o desenvolvimento das doenças, de modo geral, e especialmente, da hipertensão arterial ${ }^{18}$, demonstrando a necessidade de maior incremento na produção do cuidado na perspectiva de valorização das singularidades e subjetividades que permeia a interação interpessoal, com o intuito de deflagrar mudanças no estilo de vida para controlar, adequadamente, a doença.

No tocante aos profissionais de saúde, o tempo de serviço e as qualificações tornam-se uma força propulsora na produção do cuidado, contribuindo para atender às necessidades de saúde individual e coletiva. No campo empírico, evidencia-se a importância ${ }^{19}$ da pósgraduação para a qualificação profissional e mudanças na prática na ESF, com reflexos na melhoria dos serviços prestados à população.

Desse modo, o trabalho ${ }^{20}$ resolutivo em saúde baseia-se no cuidado corresponsável, em que prevaleça o protagonismo da equipe multiprofissional, no sentido de aprofundar os saberes e as práticas no campo da saúde. Essa ação pressupõe produção de vínculos interpessoais e contratuais, além de autonomia no processo de trabalho na atenção primária.

0 acolhimento traz consigo grandes potencialidades capazes de desenvolver e fortalecer afetos no contexto da saúde, em especial, no nível da atenção básica ${ }^{21} \mathrm{o}$ acolhimento e o vínculo, ferramentas fundamentais para o estabelecimento da confiança com o usuário ${ }^{22}$.

0 acolhimento é uma ação que deve existir em todas as relações de cuidado, no vínculo entre trabalhadores de saúde e usuários, na prática de receber e escutar as pessoas, e deve ser estabelecido como uma ferramenta que: possibilite a humanização do cuidado; amplie o acesso da população aos serviços de saúde; assegure a resolução dos problemas; coordene os serviços; e vincule a efetivação de relações entre profissionais e usuários ${ }^{23}$. À vista disso, necessário se faz que os serviços de saúde se organizem para acolher, atender, escutar e solucionar a maioria dos problemas de saúde da população adscrita, responsabilizando-se por esta população, fazendo os encaminhamentos necessários para outros pontos de atenção da rede. 
No decorrer das observações, evidenciaram-se trocas comunicacionais que permitiam os hipertensos expressarem suas angústias, medos e dúvidas, sendo alicerçada pela escuta e respeito, culminando com o cuidado. No entanto, os profissionais de saúde necessitam fortalecer o diálogo no campo das tecnologias leves, cujo foco está direcionado para o trabalho vivo em ato, para aprimorar a produção do cuidado e a ambiência relacional, ampliando o processo de comunicação sob a perspectiva da intersubjetividade.

A produção desse tipo de tecnologia acontece no momento de encontro entre o profissional e o usuário na oferta de serviços em saúde, denominando essa produção como trabalho vivo em ato ${ }^{11}$. Sendo assim, necessário se faz que os profissionais da ESF percebam a essencialidade do cuidado ${ }^{24}$, da integralidade e da atenção primária no Sistema Único de Saúde (SUS); sua articulação para um processo de produção da saúde que resgate o ser humano como foco das práticas em saúde.

Então, a APS é um ambiente fértil para um trabalho que proporciona interação social, que possibilita a construção da saúde com a participação de diferentes saberes, valorização da construção e estabelecimento de tecnologias relacionais ${ }^{11}$. Para isso, os profissionais da ESF devem estar abertos às mudanças e fortalecer as tecnologias relacionais para maior efetivação nas práticas do cotidiano nos serviços de saúde. 0 potencial dessas tecnologias em consonância com o trabalho vivo em ato é alicerce fundamental à produção do cuidado, sendo substancial no processo do trabalho em saúde para que as relações se tornem mais acolhedoras, humanizadas e integralizadas.

A ênfase na efetivação das tecnologias leves do trabalho vivo em ato na saúde sedimenta os laços de confiança e vínculo, interferindo positivamente na afetividade e efetividade das relações intersubjetivas, contribuindo para melhoria na qualidade do cuidado produzido por todos os que fazem parte da equipe de saúde, principalmente, pela enfermeira que, pelo contato $^{11}$ frequente com os usuários que chegam até as unidades de saúde, em especial na atenção básica, possui no bojo de sua profissão capacidade teórica e técnica para o estabelecimento da aplicabilidade dos preceitos defendidos na construção das relações, bem como do vínculo, autonomia, responsabilização e acolhimento, como medidas reorganizadoras da atenção e qualidade em saúde.

Ademais aos aspectos afetivos, as observações demonstraram relações de atenção, ajuda, apoio e preocupação na interação interpessoal, refletida por elementos essenciais à tessitura do cuidado, como a empatia, o respeito mútuo, o vínculo, a confiança e o acompanhamento do hipertenso nas suas reflexões.

A capacidade de empatia está relacionada aos sentimentos de confiança, envolvimento emocional e respeito mútuo que ocorrem no relacionamento interpessoal, criando espaços para relações mais horizontais de cuidado 23 .

Uma atitude empática é fator primordial nas relações interpessoais, contribuindo para um cuidado de qualidade, permeado por laços de confiança e acompanhamento adequado do hipertenso em suas reflexões. 0 cuidado requer do profissional que deseja prestá-lo alguns atributos necessários, sendo eles: a ética nas relações humanas, a solidariedade e a confiança, que permitem a pessoa aprender a lidar com o mundo, resolvendo os problemas, incluindo respeito, honestidade, consciência, fé e esperança e, o acompanhamento implica propiciar um processo de reflexão que produza as decisões autônomas dos usuários ${ }^{24,25}$.

No espaço das práticas dos profissionais de saúde se evidenciou a presença desses elementos emanados na interação interpessoal, principalmente pela Enfermeira, que com habilidades empáticas potencializa as relações, a confiança, o respeito mútuo, a escuta qualificada e o vínculo, na perspectiva de um cuidado acolhedor e humanizado. Ademais, práticas $^{11}$ exercidas pela enfermagem no campo da APS, apontam para uma abordagem diferenciada capaz de valorizar a individualidade de cada ser.

No entanto, ainda se visualizou uma atenção centrada na doença, medidas prescritivas e orientações para controle da doença, necessitando, portanto, superar essas lacunas para 
melhor direcionamento das práticas do cuidado na ESF. Para isso, necessário se faz que os profissionais de saúde fortaleçam as relações interpessoais na perspectiva das tecnologias leves do trabalho vivo em ato na saúde, dispositivos imprescindíveis à produção do cuidado.

Partindo dessa premissa, torna-se essencial a criação de espaços coletivos de discussão nas equipes de saúde e a construção de ações de cuidado que se mobilizem para atender às demandas da comunidade, considerando-se ser fundamental a realização de mudanças no processo de trabalho em saúde, buscando a efetivação dos princípios do SUS e a utilização das tecnologias em saúde adequadas para cada estação do cuidado ${ }^{26}$.

A eficácia da atenção à saúde se remete às soluções reais da convivência urbana e do acesso integral aos cuidados de saúde ${ }^{27}$. Sendo assim, profissionais de saúde e hipertensos da ESF, enquanto acompanham e são acompanhados, cuidam e são cuidados, dando ênfase às subjetividades do cuidado, devem impulsionar no processo de trabalho as tecnologias leves do trabalho vivo em ato na saúde, que fortalecem o vínculo, a autonomia e a corresponsabilização, contribuindo para o alcance de resultados promitentes nas ações e serviços de saúde.

\section{CONCLUSÃo}

Neste estudo, as práticas do cuidado são permeadas por relações acolhedoras e harmoniosas, emanadas por elementos contributivos à qualidade dos cuidados ofertados aos hipertensos, em especial, pela Enfermeira, pela sua potência na dimensão do cuidar. Apesar de ter como base essas vivências no cotidiano do trabalho em saúde, depreende-se que estas práticas ainda estão centradas na atenção à doença, nas medidas prescritivas e nas informações necessárias ao controle dos níveis pressóricos.

Para tanto, o enfrentamento da cronicidade requer investimentos na promoção da saúde, permeado com uma comunicação efetiva que possibilite uma abordagem multiprofissional com maior interação interpessoal, para que aconteça uma melhor compreensão da hipertensão e suas complicações. Em sendo assim, necessário se faz que os diversos sujeitos envolvidos no relacionamento terapêutico tenham um olhar ampliado e humano, entendendo que a produção do cuidado deve ir mais além do que uma terapêutica estabelecida, abrindo possibilidades para uma promoção emancipatória da saúde.

Com isso é preciso os profissionais da ESF avivarem o uso das tecnologias leves no trabalho vivo em ato na saúde, pois revitalizam as práticas do cuidado e tonificam o trabalho da equipe, produzindo mudanças nos sujeitos e nas questões alusivas à subjetividade. 0 reconhecimento da importância dessas tecnologias potencializa o atuar e o fazer na saúde, concentrando potencialidades que consideram as subjetividades e singularidades desses sujeitos nas relações interpessoais estabelecidas nos processos de trabalho em saúde.

A pesquisa tem como limitações o fato de ter sido realizada apenas em uma unidade de saúde do município, não sendo possível uma maior compreensão dessa problemática na dinâmica dos processos de trabalhos nos demais territórios da atenção básica, nem tampouco fazer comparações com outros estudos de maior dimensão. Mas aponta-se a importância deste estudo na compreensão da equipe pesquisada que pode ser encontrada em outras realidades.

Sugere-se assim, que outras pesquisas sejam realizadas, pois reflexões sobre essa temática precisam ser aprofundadas para o alcance de resultados mais efetivos e eficazes no contexto do SUS.

\section{REFERÊNCIAS}

1. Silva SS, Assis MMA. Family health nursing care: weaknesses and strengths in the Unified Health System. Rev Esc Enferm USP [Internet]. 2015 [citado em 10 dez 2018]; 21(3):366-70. 49(4):603609. Disponível em: https://www.scielo.br/pdf/reeusp/v49n4/0080-6234-reeusp-49-040603.pdf 
2. Silva AA, Terra MG, Mota MGC, Leite MT, Padoin SMM. Enfermagem e cuidado de si: percepção de si como corpo existencial no mundo. Rev Enferm UERJ [Internet]. 2013 [citado em 10 dez 2018]; 21(3):366-70. Disponível em: http://www.facenf.uerj.br/v21n3/v21n3a15.pdf

3. Feuerwerker LCM. Micropolítica e saúde: produção do cuidado, gestão e formação. Porto Alegre: Rede UNIDA; 2014. 174p. (Micropolítica do trabalho e o cuidado em saúde).

4. Carvalho MN, Franco TB. Cartografia de serviços de saúde mental: produção de si e da cidade para desinstitucionalizar. Physis [Internet]. 2015 [citado em 04 jan 2019]; 25(3):86384. Disponível em: https://www.scielo.br/pdf/physis/v25n3/0103-7331-physis-25-0300863.pdf

5. Lampert CDT, Scortegagna SA. Subjetividade e empatia no trabalho do cuidado. Farol Rev Estud Organizac Soc. [Internet]. 2016 [citado em 04 jan 2019]; 5(2):729-58. Disponível em: https://revistas.face.ufmg.br/index.php/farol/article/view/3133

6. Broca PV, Ferreira MA. Nursing staff and nonverbal communication. REME Rev Min Enferm. [Internet]. 2014 [citado em 04 jan 2019]; 18(3):703-9. Disponível em: https://pesquisa.bvsalud.org/portal/resource/pt/lil-766037

7. Magalhães Júnior HM, Pinto HA. Primary Care as network ordinator and care coordinator: is it still utopia? Divulg Saúde Debate [Internet]. 2014 [citado em 04 jan 2019]; 51:14-29. Disponível em: http://cebes.org.br/site/wp-content/uploads/2014/12/Divulgacao-51.pdf

8. Merhy EE. Saúde: a cartografia do trabalho vivo. 4ed. São Paulo: Hucitec Editora; 2007. 189p.

9. Almeida Q, Fófano GA. Tecnologias leves aplicadas ao cuidado de enfermagem na unidade de terapia intensiva: uma revisão de literatura. HU Rev. [Internet]. 2016 [citado em 09 jan 2019]; 42(3):191-6. Disponível em: https://periodicos.ufjf.br/index.php/hurevista/article/view/2494

10. Oliveira JSB, Suto SS, Silva RS. Tecnologias leves como práticas de enfermagem na atenção básica. Rev Saúde.Com [Internet]. 2013 [citado em 12 dez 2019]; 12(2):613-21. Disponível em: http://www.uesb.br/revista/rsc/ojs/index.php/rsc/article/view/379/383

11. Silva JAM, Peduzzi M, Orchard C, Leonello VM. Interprofessional education and collaborative practice in Primary Health Care. Rev Esc Enferm USP [Internet]. 2015 [citado em 12 dez 2019]; 49(Esp 2):16-24. Disponível em: https://www.scielo.br/pdf/reeusp/v49nspe2/en_1980-220Xreeusp-49-spe2-0016.pdf

12. Lakatos EM, Marconi MA. Fundamentos de metodologia científica. 8ed. São Paulo: Atlas; 2017.

13. Stefanelli MC, Carvalho EC. A contribuição nos diferentes contextos da enfermagem. 2ed. Barueri, SP: Manole; 2012.

14. Bardin L. Análise de conteúdo. Lisboa: Edições 70; 2011.

15. Conselho Nacional de Saúde (Brasil). Resolução no 466, de 12 de dezembro de 2012. Trata de pesquisas em seres humanos e atualiza a resolução 196 [Internet]. D.O.U., Brasília, DF, 13 dez 2012 [citado em 12 dez 2019]. Disponível em: http://conselho.saude.gov.br/resoluces/2012/reso466.pdf

16. Radovanovic CAT, Santos LA, Carvalho MDB, Marcon SS. Hipertensão arterial e outros fatores de risco associados às doenças cardiovasculares em adultos. Rev Latinoam Enferm. [Internet]. 2014 [citado em 12 dez 2019]; 22(4):547-53. Disponível em: http://www.scielo.br/pdf/rlae/v22n4/pt_0104-1169-rlae-22-04-00547.pdf/

17. Andrade SSA, Stopa SR, Brito AS, Chueri OS, Szwarcwald SL, Malta DC. Prevalência de hipertensão arterial autorreferida na população brasileira: análise da Pesquisa Nacional de Saúde, 2013. Epidemiol Serv Saúde [Internet]. 2015 [citado em 12 dez 2019]; 24(2):297-304. DOI: http://dx.doi.org/10.5123/S1679-49742015000200012

18. Araújo TME, Martins GBF, Leal MSC, Souza ATS, Sousa AS, Freire VS. Prevalência da hipertensão arterial sistólica entre caminhoneiros que trafegam pela cidade de Teresina. SANARE [Internet]. 2015 [citado em 10 nov 2019]; 14(1):38-45. Disponível em: https://sanare.emnuvens.com.br/sanare/article/view/606

19. Oliveira MPR, Menezes IHCF, Sousa LM, Peixoto MRG. Training and Qualification of Health Professionals: factors associated to the quality of primary care. Rev Bras Educ Méd. [Internet]. 2016 [citado em 10 nov 2019]; 40(4):547-59. Disponível em: https://www.scielo.br/pdf/rbem/v40n4/1981-5271-rbem-40-4-0547.pdf 
20. Costa JP, Jorge MSB, Vasconcelos MGF, Paula ML, Bezerra IC. Resolubilidade do cuidado na atenção primária: articulação multiprofissional e rede de serviços. Saúde debate [Internet]. 2014 [citado em 13 jan 2019]; 38(103):733-43. Disponível em: https://www.scielo.br/pdf/sdeb/v38n103/0103-1104-sdeb-38-103-0733.pdf

21. Garuzi M, Achitti MCO, Sato CA, Rocha SA, Spagnuolo RS. Acolhimento na Estratégia Saúde da Família: revisão integrativa. Rev Panam Salud Publica [Internet]. 2014 [citado em 13 jan 2019]; 35(2):144-9. Disponível em: https://www.scielosp.org/pdf/rpsp/v35n2/a09v35n2.pdf

22. Girão ALA, Freitas CHA. Usuários hipertensos na atenção primária à saúde: acesso, vínculo e acolhimento à demanda espontânea. Rev Gaúcha Enferm. [Internet]. 2016 [citado em 13 jan 2019]; 37(2):e60015.

Disponível

em: http://seer.ufrgs.br/index.php/RevistaGauchadeEnfermagem/article/view/60015/37421 23. Lopes AS, Vilar RLA, Melo RHV, França RCS. The hospitality in Primary Health Care: relations of reciprocity between workers and users. Saúde Debate [Internet]. 2015 [citado em 13 jan 2019]; 39(104):114-23. DOI: 10.1590/0103-110420151040563

24. Camut L. Cuidado, integralidade e atenção primária: articulação essencial para refletir sobre o setor saúde no Brasil. Saúde Debate [Internet]. 2017 [citado em 07 abr 2020]; 41(115):1177-86. DOI: http://dx.doi.org/10.1590/0103-1104201711515

25. Valverde C. Comunicación terapéutica em enfermaría. Madri: DAE; 2007.

26. Engela MHT, Rodarte AC, Rotondaro Júnior A, et al. Uso das tecnologias em saúde na atenção básica às pessoas em condições de hipertensão arterial sistêmica. Rev Pesqui. (Univ. Fed. Estado Rio J.) [Internet]. 2018 [citado em 07 abr 2020]; 10(1):75-84. DOI: http://dx.doi.org/10.9789/2175-5361.2018.v10i1.75-84

27. Pinto AGA, Lucetti MDL, Santana KFS, Bezerra AM, Viana MCA, Jorge MSB. Gestão do cuidado e da clínica. REFACS [Internet]. 2019 [citado em 06 jan 2020]; 7(1):23-31. Disponível em: http://seer.uftm.edu.br/revistaeletronica/index.php/refacs/article/view/2169/pdf

\section{CONTRIBUIÇÕES}

Geanne Maria Costa Torres e Maria Irismar de Almeida contribuíram no delineamento do estudo, na coleta e análise de dados, redação e revisão. Inês Dolores Teles Figueiredo, José Auricélio Bernardo Cândido e Antonio Germane Alves Pinto participaram na redação e revisão.

\section{Como citar este artigo (Vancouver)}

Torres GMC, Figueiredo IDT, Cândido JAB, Pinto AGA, Almeida MI. Produção do cuidado e as relações intersubjetivas com usuários hipertensos na Estratégia Saúde da Família. REFACS [Internet]. 2020 [citado em inserir dia, mês e ano de acesso]; 8(4):837-846. Disponível em: inserir link de acesso. DOI: inserir link do DOI.

\section{Como citar este artigo (ABNT)}

TORRES, G. M. C.; FIGUEIREDO, I. D. T.; CÂNDIDO, J. A. B.; PINTO, A. G. A.; ALMEIDA, M. I. Produção do cuidado e as relações intersubjetivas com usuários hipertensos na Estratégia Saúde da Família. REFACS, Uberaba, MG, v. 8, n. 4, p. 837-846, 2020. Disponível em: inserir link de acesso. Acesso em: inserir dia, mês e ano de acesso. DOI: inserir link do DOI.

\section{Como citar este artigo (APA)}

Torres, G.M.C., Figueiredo, I.D.T., Cândido, J.A.B., Pinto, A.G.A., \& Almeida, M.I. (2020). Produção do cuidado e as relações intersubjetivas com usuários hipertensos na Estratégia Saúde da Família. REFACS, 8(4), 837-846. Recuperado em inserir dia, mês e ano de acesso de inserir link de acesso. DOI: inserir link do DOI. 